GEOUSP - Espaço e Tempo, São Paulo, No 28, pp. 93 - 103, 2010

\title{
REESTRUTURAÇÃO PRODUTIVA EM CIDADES MÉDIAS: UMA ANÁLISE DAS EMPRESAS INDUSTRIAIS DO OESTE PAULISTA ${ }^{1}$
}

Maria Terezinha Serafim Gomes*

\section{Resumo:}

O presente texto aborda o processo de reestruturação produtiva em empresas industriais, tendo como referência o aglomerado urbano fora do espaço metropolitano. Tem como objetivo revelar as mudanças na organização e gestão do processo produtivo, bem como do trabalho em empresas industriais de cidades médias do Oeste Paulista no contexto da reestruturação produtiva.

Analisando o processo de reestruturação produtiva fora do espaço metropolitano observou-se que as empresas industriais do Oeste Paulista estão passando por um processo de reestruturação implementando práticas e métodos mais flexíveis ao mesmo tempo em que permanecem com as práticas tradicionais. Dessa forma, há uma coexistência do "novo" e do "velho" no interior da mesma empresa.

Palavras-chave: reestruturação produtiva; indústria; cidades médias; Oeste Paulista.

\begin{abstract} restructuring.

\section{Introdução}

No Brasil, o processo de reestruturação produtiva ocorre pari passu aos novos padrões de competitividade internacional e às mudanças econômicas que ocorreram no país, à crise do padrão industrial baseado no desenvolvimentismo,a recessão e ao desemprego no final dos anos 1970.
\end{abstract}

The present text approaches the process of productive restructuring in industrial companies, having as reference the urban agglomeration outside the metropolitan area. The objective is to reveal the changes in the organization and management of the productive process, as well as the labor in the industries of middle-size cities in the west region of São Paulo State (Brazil), in a context of productive

In the analyze of this process outside the metropolitan area has been observed that the industries of the west region of São Paulo are experiencing a restructuring process where practical and more flexible methods has been implemented at the same time as remains the traditional practices. Therefore, there is a coexistence of the "new" and the "old" in the inner of this industries.

Key-words: productive restructuring; industry; middle-size cities; west region of São Paulo (Brazil).

Inicialmente, as propostas de modernização das empresas se concentravam na adoção dos CCQs (círculos controle qualidade), sem que elas se preocupassem em alterar de modo significativo as formas de organização do trabalho ou em investir mais efetivamente em novos equipamentos microeletrônicos.

Nos anos 1990, a reestruturação produtiva ganha dimensão com a abertura comercial e financeira, a política neoliberal e a

* Geógrafa, Doutora em Geografia pela Universidade de São Paulo, Profa. do curso de Geografia da UFTM, Coordenadora do Núcleo Interdisciplinar de Estudos e Pesquisas em Política, História, Espaço, Educação e Sociedade - NIEPHES /UFTM e membro do Grupo de Estudos da Dinâmica Econômica GEDE/UNICENTRO-PR. E-mail: tserafim@geografia.uftm.edu.br ou serafimgomes@ hotmail.com 
necessidade de reestruturar para inserir-se no mundo globalizado, levando as empresas buscarem por ajustes, inovações tecnológicas, novas formas de organização de produção e organização do trabalho.

Desse modo, com a abertura econômica as empresas foram "obrigadas" a buscar ajustes e inovações para concorrer no mercado internacional, colocando a indústria brasileira diante de novos desafios. Tal busca fez "sacrificar" parcelas significativas de pequenas e médias empresas que foram à falência ou adquiridas por empresas maiores de capital nacional e internacional, tendo consequências diruptivas na "classe que-vive-do-trabalho" (termo utilizado por Antunes, 1999), com a redução de postos de trabalho e deterioração das relações trabalhistas.

A reestruturação ocorre quando há gargalos para alavancar o crescimento e reprodução do capital. Neste sentido, a reestruturação produtiva em curso visa atender as necessidades do capital de se reproduzir. Ou seja, atender as necessidades das empresas industriais de competirem no mercado internacional, ou mesmo por uma questão de sobrevivência.

O processo de reestruturação produtiva em curso tem suas implicações na dinâmica espacial, no processo produtivo e na organização do trabalho, bem como no mercado de trabalho. Ele é mais sintomático nos centros industriais mais consolidados, no entanto, começa a se manifestar também nas cidades médias. Hoje, essas cidades se configuram cada vez mais em "novos espaços produtivos".

Este texto tem como objetivo abordar o processo de reestruturação produtiva em empresas industriais de aglomerados urbanos fora do espaço metropolitano. Procuramos analisar as mudanças na organização e gestão do processo produtivo, bem como do trabalho em empresas industriais de cidades médias do Oeste Paulista no contexto da reestruturação produtiva, tendo como referência as cidades de Araçatuba, Birigui, Marília, Presidente Prudente e São José do Rio Preto.
Antes de discutirmos sobre reestruturação produtiva em cidades médias, é necessário definir o que vem a ser uma "cidade média", categoria esta da rede urbana brasileira. No Brasil, a noção de "cidades médias" é de difícil consenso. Vários autores têm abordado essa temática e alguns partem do tamanho demográfico, considerando "cidades médias" aquelas que possuem entre 100 e 500 mil habitantes (IBGE) e outros partem dos papéis desempenhados por essas cidades. Dentre eles, podemos destacar: Amorim Filho (1984), Soares (1999), Amorim e Serra (2001) e Sposito (1999,2001 e 2004).

Neste trabalho, partimosdo rentendimento de cidade média, do ponto de vista do papel que ela exerce na sua região e sua relação com outros lugares, seu papel na divisão territorial do trabalho e não apenas o critério demográfico. Desta maneira, compartilhamos das ideias de Sposito (2004), pois acreditamos ser a mais atual no contexto da reestruturação produtiva. Sposito (2004,p. 338-340) destaca alguns pontos sobre a noção de "cidades médias". Nas suas palavras: As cidades médias podem, em princípio, ser definidas por: a) sua situação geográfica em relação às outras cidades de mesmo porte; b) sua distância maior ou menor das cidades de maior porte; c) número de cidades pequenas que estão em sua área de influência, já que as empresas e as instituições se orientam pelo limites entre as áreas de mercado."

Os papéis das cidades médias dependem, assim, da forma como o território que comandam e representam participa da divisão regional do trabalho que, por sua vez, é orientada pela redefinição internacional do trabalho. (p. 338) [...] O conjunto de mudanças produzidos pelo processo de concentração e centralização econômicas, com desconcentração espacial das atividades de produção e consumo, dinâmicas que se acentuam na passagem do fordismo para a acumulação flexível, tem repercussão direta nos papéis desempenhados pelas cidades médias, uma vez que as possibilidades de escolhas territoriais para o desenvolvimento de atividades produtivas e para a instalação de 
Reestruturação produtiva em cidades médias:

uma análise das empresas industriais do Oeste Paulista, pp.93 - 103

pontos de redes de consumo de bens e serviços é maior, quanto mais capitalizada for a empresa. As cidades médias têm sido escolhidas como pontos de apoio dessas empresas em suas políticas de desconcentração das atividades e de expansão das redes de comercialização de bens e serviços. (p.340)

As ideias aqui expostas se apóiam em pesquisa bibliográfica e, particularmente, na pesquisa de campo realizada em 55 empresas industriais localizadas nessas cidades médias supracitadas anteriormente.

\section{Discutindo a noção de reestruturação}

Antes de discutirmos sobre o processo de reestruturação produtiva em cidades médias, é necessário, ainda, abordar a noção de reestruturação.

Do ponto de vista gramatical, a palavra reestruturação é um substantivo e significa "ato ou efeito de reestruturar; nova estruturação".2. Sendo assim, a palavra reestruturação significaria reformular em novas bases estruturais e reorganizar.

Atualmente, a noção de reestruturação tem adquirido várias denominações: reestruturação urbana, reestruturação social, reestruturação espacial, reestruturação organizacional, reestruturação econômica, reestruturação industrial e reestruturação produtiva. Neste artigo, o enfoque será a reestruturação produtiva.

Lencioni (1998b,p.6) ao tratar de reestruturação, alerta-nos: "[...] seria um engano pensar em reestruturação como outra estrutura que se sobrepõe à anterior". Em suas palavras, essa forma de pensar "[...] Considera a estrutura como sendo estável e fixa, até o momento da ruptura; momento em que uma nova estrutura se sobrepõe a ela e a substitui".

Esta autora considera a reestruturação como movimento. Para ela, "[...] as formas anteriores não se dissolvem nesse processo de reestruturação, elas se modificam e são modificadas pela teia de relações em movimento. Tornam-se, sim, subordinadas face ao desenvolvimento dessas novas formas que reestruturam tanto a sociedade como o espaço". (LENCIONI,1998b,p.7 e 8)

Outro autor que discorda do entendimento da reestruturação como sendo algo mecânico é Soja (1993,p.194). Segundo o autor, a reestruturação não é um processo mecânico ou automático, nem tampouco seus resultados e possibilidades potenciais são predeterminados. Em sua hierarquia de manifestações, a reestruturação deve ser considerada originária de e reativa a graves choques nas situações e práticas sociais preexistentes, desencadeadora de uma intensificação de lutas competitivas pelo controle de forças que configuram a vida material. Assim, ela implica fluxo e transição, posturas ofensivas e defensivas, e uma mescla complexa e irresoluta de continuidade e mudança. Como tal, a reestruturação se enquadra entre a reforma parcial e a transformação revolucionária, entre a situação de perfeita normalidade e algo completamente diferente.

Assim, de acordo com Soja (1993) a reestruturação "[...] implica fluxos e transição" e "[...] mescla continuidade e mudanças". Desta maneira, não podemos considerar a reestruturação como algo mecânico e estático; ela é dialética. É importante analisar tal processo produtiva a partir de temporalidades.

Se as "estruturas são momentos provisórios", como afirmou Lefebvre (1971), podemos dizer que a reestruturação é um movimento ao mesmo tempo de "continuidades" e "descontinuidades".

Estamos entendendo a reestruturação produtiva como um processo de mudança espacial, social, tecnológica e organizacional. Partimos da proposição de que a reestruturação tem ritmos, movimentos e temporalidades. Assim, trataremos a reestruturação como algo dinâmico, um processo dialético, em que elementos do "novo" e do "velho" coexistem na mesma empresa, isto é, as características do fordismo e da produção flexível. Para sua análise é preciso levar em consideração as temporalidades e os resíduos que permanecem. É nesta perspectiva que se insere nosso 
entendimento do processo de reestruturação produtiva em cidades médias do Oeste Paulista.

Neste sentido, cada empresa tem temporalidade diferente. "Algumas conseguem mais inovações, processamento de informações mais rápido assegurando o gerenciamento flexível - o tempo não é apenas comprimido: é processado" (Castells, 2001). Enquanto que, em outras empresas, esse processo ocorre de forma mais lenta. Isto se deve às condições as quais se apropriam da inovação, da informação e do capital.

Desta forma, os tempos são diferentes entre empresas, instituições e homens e será diferente de lugar para lugar. Assim, Santos (2001,p.267) afirma: O tempo rápido não cobre a totalidade do território nem abrange a sociedade inteira. Em cada área, são múltiplos os graus e as modalidades de combinações. Mas, graças à globalização e a seus efeitos locais, os tempos lentos são referidos ao tempo rápido, mesmo quando este não exerce diretamente sobre os lugares ou grupos sociais.

Ao tratar de reestruturação produtiva requer atenção, pois a simples implementação de um equipamento em uma empresa não quer dizer que ela passou por um processo de reestruturação. Este é mais complexo e, por isso, admite-se compreender as mudanças na base tecnológica, organizacional, social e espacial, considerando suas temporalidades e resíduos.

Vale ressaltar que, o processo da reestruturação produtiva não atinge todos os lugares, setores ou empresas com a mesma intensidade.

Esse processo de reestruturação produtiva em curso é mais visível nas metrópoles, nas grandes cidades e centros industriais consolidados, mas é possível observar indícios também em cidades médias.

\section{O processo de reestruturação produtiva em cidades médias}

Não é demais lembrar que as transformações resultantes do processo de reestruturação produtiva fazem parte de um processo mais amplo de mudanças em âmbito global e nacional. A partir dos anos 1970, com a crise que o padrão de produção fordista desencadeou na economia mundial, um processo de transformações tecnológicas e financeiras com novas formas de organização de produção e de trabalho, bem como novas estratégias de mercados marcaram início a um movimento de reestruturação industrial nos países capitalistas avançados, buscando novos padrões de competitividade e concorrência entre mercados.

No Brasil, o processo de reestruturação produtiva se intensifica nos anos 1990 por dois fatores fundamentais: pela crise econômica no mercado interno e pela política de abertura adotada pelo governo Fernando Collor. Com efeito, a redução das tarifas de importação provocada pela abertura "forçou" as empresas a buscar por inovações mais efetivas, estratégias de produtividade e qualidade nos produtos para fazer frente à concorrência internacional, ou seja, elas procuraram estar em "sintonia" com as mudanças internacionais e os ditames da globalização.

Nesse contexto, a palavra de ordem que se impõe às empresas passou a ser a busca de competitividade, da eficiência da gestão, dos serviços e dos produtos.

Essa busca por competitividade teve implicações no quadro de funcionários das empresas, ocasionando uma "redução de cargos hierárquicos, com mais demissões nas gerências, seguida pela redução de escalões intermediários e também dos operários de chão de fábrica", conforme destacou Pires (1994,p. 13).

Assim, se, por um lado, esse imperativo de competitividade levou as empresas a buscar modernização, terceirização, organização do trabalho, por outro lado, a abertura econômica atingiu o emprego industrial nos anos 1990. Neste período, o desemprego cresceu, atingindo mais de $20 \%$ da PEA (população economicamente ativa) em algumas regiões metropolitanas. Houve também um recrudescimento da informalidade, redução do trabalho com carteira assinada, aumento do 
Reestruturação produtiva em cidades médias:

uma análise das empresas industriais do Oeste Paulista, pp.93 - 103

trabalho sem carteira assinada e do trabalho temporário, contribuindo para a precarização do trabalho.

Corroborando tais afirmações, segundo o sociólogo Ricardo Antunes (1999), o mundo do trabalho vem passando por metamorfoses: de um lado, verificou-se diminuição da classe operária industrial tradicional. Mas, paralelamente, de outro lado, efetivou-se significativa subproletarização do trabalho, decorrência das formas diversas de trabalho parcial, precário, terceirizado, subcontratado, vinculado à economia informal, ao setor de serviços etc. Verificou-se, portanto, significativa heterogeneização, complexificação e fragmentação do trabalho (p. 209). Para estas formas de trabalho, Beynon (1991) chamou de operários "hifenizados", que são aqueles que se enquadram em trabalho parcial, trabalho precário, trabalho por tempo, por hora, resultando na precarização da classe trabalhadora. Neste sentido, há uma polissemização da classe trabalhadora no mundo atual.

O processo de reestruturação produtiva parece ser mais significativo em centros industriais já consolidados e regiões metropolitanas, sobretudo em São Paulo, todavia começam ser observados alguns indícios em cidades médias. Essas cidades médias tornam-se espaços alternativos no processo de reestruturação constituindo "novos espaços industriais", já que elas possuem infraestrutura capaz de receber as novas indústrias.

A reestruturação produtiva no Oeste Paulista insere contexto das transformações na agricultura regional, da própria crise econômica que assola o país e, sobretudo, da abertura econômica dos anos 1990.

Assim, a abertura também atingiu as empresas de capital local das cidades médias da região Oeste Paulista. As empresas, não conseguindo manter-se no mercado, tiveram de fechar seus estabelecimentos ou se reestruturar e modernizar sua produção, ou ainda foram adquiridas por empresas de grande porte nacional ou grupos estrangeiros. Dessa forma, a abertura econômica foi o leitmotiv para as empresas entrarem num processo de reestruturação.

De acordo com as empresas pesquisadas nas cidades médias da região Oeste Paulista (Araçatuba, Birigui, Marília, Presidente Prudente e São José do Rio Preto), elas passam por reestruturação por duas razões: 1) questão de sobrevivência; 2) necessidade de ampliação da atuação no mercado interno e externo, bem como a busca de melhorias na qualidade de produtos frente à concorrência, desta forma, procuram se ajustar num ambiente de competitividade.

Diante das mudanças resultantes da reestruturação produtiva, as empresas buscam maior produtividade e qualidade para concorrer com outros mercados e tornarem mais competitivas. Para isto, passam a investir em inovações tecnológicas para garantir o aumento da produtividade, de forma a propiciar maior qualidade de seus produtos, bem como sua diversificação. Tais investimentos vão desde o setor produtivo até políticas de recursos humanos. O que se percebe é que a inovação é a mola propulsora para as empresas ampliarem seus mercados e parece ter sido um dos fatores essenciais para proporcionar uma nova característica à região do Oeste Paulista e inserila no processo de reestruturação produtiva.

Assim, nesse cenário da reestruturação produtiva, as empresas buscam estratégias que visam à produtividade, à qualidade e à competitividade. A flexibilidade é a palavra de ordem, tanto no âmbito da produção quanto no trabalho, assim novos métodos e técnicas de gestão e inovação são implementados nas empresas para buscar melhorias e atingir novos mercados. Dessa forma, a inovação torna-se um elemento importante para as empresas no contexto atual da globalização e da reestruturação produtiva.

Vários autores, entre eles Benko (1996) e Schumpeter (1989), afirmam que a dimensão tecnológica é essencial na dinâmica econômica. 
Não queremos aqui ser reducionista à tecnologia, explicar a reestruturação produtiva no Oeste Paulista apenas pela implementação de inovação tecnológica, mas acreditamos que a inovação foi importante para modernização e para o dinamismo das empresas industriais da região.

Dessa maneira, compartilhamos das ideias de Schumpeter para entender o processo de reestruturação produtiva, com a implementação de inovações no processo produtivo e do trabalho, pois, assim, acreditamos que as inovações foram importantes para as empresas industriais do Oeste Paulista.

Nesse contexto, a inovação está sendo cada vez mais necessária para que a empresa possa permanecer no mercado ou ampliá-lo. Tal necessidade acaba sendo uma condição sine qua non de permanência no mercado a partir dos anos 1990 com a abertura econômica, como já afirmamos anteriormente.

Esse processo de reestruturação produtiva em curso resultante de um conjunto de mudanças na organização e gestão do processo produtivo com a implementação de inovações tecnológicas, métodos e técnicas de produção e novos padrões de gestão, bem como a organização do trabalho não se apresenta de modo uniforme em todas as empresas industriais.

Essa busca por transformações ainda é seletiva. A incorporação de inovações tecnológicas, métodos e técnicas de produção diferem segundo o porte da empresa, sendo mais intenso nas médias e grandes empresas e também naquelas que exportam seus produtos.

Como já afirmamos anteriormente, a necessidade de incorporar tais mudanças está relacionada à sobrevivência e à ampliação do mercado de atuação e também à própria concorrência entre as empresas locais e regionais. Muitas empresas que não conseguiram se inserir no novo de padrão desenvolvimento fecharam seus estabelecimentos ou foram adquiridas por empresas nacionais ou estrangeiras.
A abertura econômica dos anos 1990 deu impulso ao processo de reestruturação das empresas industriais do Oeste Paulista, quando passaram a buscar por inovações. Isso ficou claro na pesquisa de campo junto às empresas, em que elas declararam a implementação de mudanças, sobretudo a partir dos anos 1990 e 2000.

Sendo assim, as empresas buscam estratégias, técnicas organizacionais para proporcionar melhores índices de qualidade e de produtividade, criando assim condições para enfrentar a concorrência.

No que se refere ao tipo de inovações tecnológicas implementadas pelas empresas industriais das cidades médias do Oeste Paulista, do total de 55 empresas pesquisadas, verificou-se que 49 empresas, ou seja, 89,09\% implementaram algum tipo de inovação, sendo maior nas empresas de porte médio e grande; $27 \%$ tiveram a inovação de produto; $27 \%$ tiveram a inovação de produto de natureza incremental; $18 \%$ tiveram a inovação de processo; $17 \%$ tiveram a inovação de P\&D (pesquisa \& desenvolvimento); $5 \%$ tiveram a inovação de produto de natureza significativa; $3 \%$ declararam que não tiveram nenhum tipo de inovação tecnológica e 3\% não responderam.

Acreditamos que a teoria de Schumpeter é pertinente para compreendermos o papel do empresário-inovador na implantação de inovações nas empresas no atual processo de reestruturação produtiva, em que as empresas estão buscando cada vez mais qualidade, produtividade e competitividade. Sendo assim, acredita-se que a inovação é fundamental para competição das empresas.

Além disso, para esse autor é possível superar as crises por meio de modernização e inovações tecnológicas. Assim, no período de crise as empresas buscam a inovação como saída. Deste modo, todos os empresários são estimulados a inovar, sendo a inovação um elemento fundamental para reprodução do capital.

Desta forma, a ideia de Schumpeter, de que a inovação é importante para do desenvolvimento econômico é bastante 
Reestruturação produtiva em cidades médias:

uma análise das empresas industriais do Oeste Paulista, pp.93 - 103

interessante para compreender o processo de reestruturação produtiva, resultante da abertura econômica, pois as empresas foram obrigadas a se modernizar, diversificar seus produtos como forma de sobrevivência.

Muitas empresas inovam por causa de suas concorrentes. Nesse sentido, Porter (1999) afirma que a transmissão do conhecimento favorece a competição local, pois a concorrência estimula a imitação e a inovação.

Nesse processo de reestruturação em curso as empresas do Oeste Paulista além das inovações tecnológicas de processo e de produto e da certificação ISO, elas buscam no âmbito da gestão e organização do processo produtivo, os seguintes métodos e técnicas: just in time, ${ }^{3}$ kanban $^{4}$, kaizen ${ }^{5}$, sistema CAD/CAM ${ }^{6}$, sistema CAD/CAE, Controle estatístico do processo $^{7}$,programa de Qualidade Total, células de produção ${ }^{8}$, layout, redução do tamanho da planta, parcerias com fornecedores, desverticalização da produção, automatização, eliminação de estoques, desativação de linhas de produção e ampliação de produtos.

Cabe destacar que, essas inovações e métodos e técnicas foram implementados, sobretudo a partir dos anos 1990 e 2000. Sendo assim, observa-se que o processo de reestruturação produtiva é bastante recente.

Tais mudanças também implicam uma nova conduta empresarial. Desse modo, os programas como controle de qualidade total acabam por estimular novas práticas, novos comportamentos e disciplina entre os trabalhadores no interior da fábrica, fazendo com que eles colaborem com os objetivos da empresa. Há assim uma corresponsabilidade do trabalhador no processo produtivo.

Dessa forma, na verdade, o controle sobre o trabalhador acaba sendo sutilmente utilizado pelas novas políticas de recursos humanos em que o trabalhador é visto como um "colaborador". Além disso, na participação do trabalhador, o savoir faire é adquirido, sem qualquer ônus para empresa.

A literatura confirma as evidências empíricas de que as transformações ocorridas no global e no nacional no âmbito do processo de produção e do trabalho também ocorrem no interior das empresas do Oeste Paulista,ainda que numa dimensão menor e em ritmo menos acelerado. O que podemos afirmar é que há uma coexistência de vários sistemas de produção industrial, ou seja, de formas de organização de produção e do trabalho do sistema fordista de produção e também da produção flexível.

Nesta direção, David Harvey (1989) ao discutir a acumulação flexível, afirma a existência de uma combinação de processos produtivos articulando o fordismo com processos flexíveis e tradicionais.

E, também, Castro (1994) e Gitahy (1994) afirmaram que há a convivência do "novo paradigma" com as velhas práticas de gestão do trabalho, constituindo sistemas mistos até mesmo no interior de uma mesma planta.

De modo geral, as práticas tradicionais de produção e de trabalho observadas nas empresas industriais fazem parte da própria indústria brasileira, que ainda permanece com práticas tayloristas/fordistas. Já as práticas inovadoras e flexíveis fazem parte das mudanças que ocorrem na organização do trabalho no contexto mundial, que vai se difundindo, como uma forma de inserir no mundo globalizado.

Assim, analisando as empresas industriais das cidades médias do Oeste do Estado de São Paulo (Araçatuba, Birigui, Marília, Presidente Prudente e São José do Rio Preto), verificou-se que ao mesmo tempo em que estão buscando inovações tecnológicas e novos métodos e técnicas de gestão e organização da produção e do trabalho denominadas "flexíveis", coexistem com práticas tradicionais denominadas "fordistas".

Por exemplo, em Araçatuba as empresas industriais pesquisadas apontaram uma tendência mais fordista do ponto de vista da produção com a uniformidade e padronização da produção. Já do ponto de vista da organização do trabalho, as empresas apresentaram características mais flexíveis.

Em Birigui, observou-se nas empresas uma tendência mais flexível no processo produtivo com o uso de métodos e técnicas da 
produção flexível como também na organização do trabalho com uso da polivalência e gestão participativa, mas as empresas também apresentaram características fordistas, tanto na produção como na gestão do trabalho.

A incorporação de novas técnicas organizacionais tem levado à intensificação do trabalho e ganha dimensão, a chamada "polivalência", na qual os trabalhadores são levados a assumir um conjunto de novas tarefas (a título de exemplo o atendimento de mais uma máquina, além de realizar tarefas de manutenção).

Segundo Alves (2000,p. 130) "[...] a polivalência operária instaurada com o novo sistema de produção, tornou-se apenas a capacidade de alimentar mais de um tipo de máquinas, não implicando para o operário a posse de uma série de múltiplas habilidades."

Nas cidades de Marília e São José do Rio Preto, as empresas industriais pesquisadas apresentaram características fordistas e flexíveis no interior da mesma empresa, mostrando uma tendência mais flexível pelo uso de técnicas e métodos de produção, como just in time, kanban, células de produção, controle estatístico do processo, produção em pequenos lotes e, também, na organização do trabalho com o desenvolvimento de múltiplas tarefas, Iongo treinamento no trabalho, organização mais horizontal é, aprendizagem no mesmo, trabalho polivalente, gestão participativa, ênfase na corresponsabilidade do trabalhador e círculos de controle de qualidade, os CCQs.

Em Presidente Prudente, as empresas industriais apresentaram características mais fordistas na produção, entre elas podemos destacar: produção em massa de bens homogêneos, uniformidade e padronização da produção, presença de grandes estoques da produção e detecção tardia dos erros na produção.

As características fordistas também foram observadas na organização do trabalho, como podemos mencionar: a separação do trabalho manual do intelectual, realização de uma única tarefa por trabalhador, alto grau de especialização de tarefas, pouco ou nenhum treinamento no trabalho, organização vertical no trabalho, trabalho parcelar e fragmentado, trabalho especializado, hierarquização, controle do tempo pelo cronômetro.

Não obstante, as empresas apresentarem características mais fordistas, elas também apresentaram características flexíveis na organização do trabalho com o desenvolvimento de múltiplas tarefas, longo treinamento no trabalho, organização mais horizontal no trabalho, aprendizagem no trabalho, trabalho polivalente, gestão participativa, ênfase na coresponsabilidade do trabalhador e círculos de controle de qualidade, os CCQs.

A introdução pelas empresas desses métodos e técnicas no processo produtivo visa à racionalização e à melhoria da qualidade da produção, bem como evitar os desperdícios e reduzir custos de insumos e materiais.

Tais mudanças observadas no interior das empresas industriais repercutiram no mercado de trabalho local com o aumento do trabalho temporário, terceirizado e estagiários, contribuindo para a precarização do trabalho.

Os dados empíricos revelaram que as empresas industriais do Oeste Paulista estão passando por um processo de reestruturação implementando práticas e métodos mais flexíveis ao mesmo tempo em que permanecem com as práticas tradicionais. Desse modo, é possível observar características fordistas e flexíveis no interior da mesma unidade produtiva.

Essas mudanças no processo produtivo e gestão, bem como na organização do trabalho não ocorrem com a mesma intensidade em todas as empresas industriais dessas cidades médias. Há diferença segundo o porte da empresa, as grandes e as que foram instaladas recentemente são mais susceptíveis a essas mudanças. Algumas pequenas empresas ainda resistem a essas mudanças e à incorporação ao mundo globalizado, apresentando características fordistas/tayloristas. Neste sentido, pode-se dizer que toda vez que algo "novo" chega num lugar, causa impacto e também resistência. Da mesma forma, podemos dizer que algumas empresas resistem a tais 
Reestruturação produtiva em cidades médias:

uma análise das empresas industriais do Oeste Paulista, pp.93 - 103

mudanças ou vão adquirindo-as de maneira mais lenta, o que pode dificultar a sua participação no mercado cada vez mais competitivo ou sua própria sobrevivência.

Ainda, essas mudanças têm como fulcro a necessidade de ampliar ou assegurar sua permanência no mercado. Já que aquelas empresas industriais que não buscam inovações, dificilmente conseguem se manter no mercado. Ademais, as mudanças relacionadas à organização de trabalho são para melhor desempenho do trabalhador e para facilitar o próprio relacionamento entre empresa e funcionários e, também, para a manipulação dos equipamentos que exigem certo grau de conhecimento.

\section{Considerações finais}

Ao tratar da reestruturação produtiva não se pode afirmar que todas as empresas são flexíveis, pois todas elas convivem com o "novo" e o "velho". A incorporação de inovações tecnológicas, métodos e técnicas diferem segundo o porte da empresa, sendo maior nas grandes e médias empresas, e naquelas que exportam seus produtos e também nas empresas que foram instaladas recentemente nas cidades pesquisadas trazem consigo estratégias, estimulando as empresas de capital local a se modernizar para torná-las mais competitivas.

A pesquisa demonstrou que algumas micro e pequenas empresas possuem resistências às mudanças, apresentando assim características fordistas/tayloristas. Neste aspecto, os ritmos de implementação de inovações das empresas não têm as mesmas temporalidades, segundo o porte.

Desse modo, o processo de reestruturação produtiva possui temporalidades e ritmos diferentes segundo o lugar e o porte das empresas.

A reestruturação produtiva no Oeste Paulista não tem a mesma intensidade que a reestruturação da metrópole, pois ocorre numa velocidade menor. Destarte, o ritmo das transformações difere segundo os lugares e também o capital investido pelos agentes produtivos etc.

No processo de reestruturação em curso em empresas industriais do Oeste Paulista, não quer dizer que a estrutura anterior deixou de existir, ela existe, mas com transformações. Ou seja, há uma coexistência das características tradicionais e modernas nas empresas.

Enfim, tais transformações resultantes do processo de reestruturação produtiva acarretam mudanças nas cidades médias. Assim, as transformações que ocorrem na indústria da região Oeste com a implantação de novas empresas de capital externo, com o surgimento de novos ramos industriais, com a incorporação de novos métodos e técnicas de gestão e organização do processo produtivo e do trabalho, com a busca de novos mercados e nova inserção dessas cidades médias na divisão territorial do trabalho, contribuíram para um novo conteúdo no contexto da reestruturação produtiva.

\section{Notas}

1 Texto é baseado nas discussões apresentadas na tese de doutorado defendida junto ao Programa de Pós-Graduação de Geografia Humana, da Universidade de São Paulo -USP, 2007. Data de elaboração do artigo: 29/09/ 2009.

2 HOUAISS, A. Dicionário eletrônico da língua portuguesa. São Paulo: Ed. Objetiva. 2001 (CD $-\mathrm{ROM})$.

3 Just in time: sistema de produção criado pelos japoneses que tem por objetivo produzir bens e/ou serviços exatamente no momento em que são necessários, com qualidade e sem desperdícios. Para Salerno (1992, p.105) o sistema just in time, que incorpora as células e propõe uma forma de ordenar o fluxo de materiais e de informações na produção como um todo, é outro na ordem do dia.

4 Kanban: sistema de controle da reposição de mercadorias semelhante ao sistema de sinalização do trânsito. 
${ }^{5}$ Kaizen: técnica de origem japonesa, conhecida como grupo de melhorias em todos os setores é importante no processo produtivo.

6 CAD - Computer-Aided Design (Projeto Auxiliado por Computador) auxiliam a criação, modificação, análise ou otimização de um projeto. O software desses sistemas é baseado em interface gráfica orientada ao usuário.

CAM - Computer-Aided Manufacturing (Fabricação Auxiliada por Computador) pode ser definido como o uso de sistemas computacionais para planejar, gerenciar e controlar as operações de uma planta de fabricação através de uma interface direta ou indireta com os recursos de produção da planta.

CAE: As atividades de análise de engenharia são auxiliadas pelos sistemas CAE - ComputerAided Engineering (Engenharia Auxiliada por Computador).

\section{Bibliografia}

ALVES, Giovanni. O novo (e precário) mundo do trabalho: reestruturação produtiva e crise do sindicalismo. São Paulo: Boitempo,2000. 365p.

ANTUNES, Ricardo. Anotações sobre o capitalismo recente e a reestruturação produtiva no Brasil. In: ANTUNES, Ricardo; SILVA, Maria A. Expressão Popular. 2004, p.13-28.

Os sentidos do trabalho: ensaio sobre a afirmação e a negação do trabalho. São Paulo: Boitempo, 1999. $261 \mathrm{p}$

BENKO, George. Economia, espaço, globalização na aurora do século XXI. São Paulo: Hucitec, 1996. $266 \mathrm{p}$.

BEYNON, Huw. As práticas do trabalho em mutação. In: ANTUNES, Ricardo. (org.). Neoliberalismo, trabalho e sindicatos. 2.ed. São Paulo: Boitempo, 1998. p. 9-38.

CARLEIAL, Liana; VALLE, Rogério (Orgs). Reestruturação Produtiva e o Mercado de Trabalho no Brasil. São Paulo: Hucitec/ABET, 1997. 508p
7 Controle estatístico de processo (CEP): caracterizado pela integração de controle de qualidade à produção, através da utilização de conceitos básicos de estatísticos na inspeção das peças, que passa a ser feita pelos próprios operadores de máquinas.

8 Célula de fabricação: consiste em organizar as máquinas a partir do fluxo da produção, permitindo uma sensível diminuição do lead time (tempo total de fabricação de uma peça) e dos estoques intermediários (tendo em vista, que a integração entre as várias máquinas de cada célula elimina o tempo que as peças têm normalmente que aguardam nas prateleiras antes de serem usinadas por cada máquina. (Leite,2003, p.70).

CARVALHO, Ruy de Quadros e SCHMITZ, Hubert. O fordismo está vivo no Brasil. Novos Estudos. n. 27, junho. 1999, p.148-156.

CASTELLS, Manuel. A sociedade em Rede A era da Informação: Economia, Sociedade e Cultura.v. 1. $4^{a}$ ed. São Paulo: Paz e Terra, 1999.617p

CASTRO, Nadya Araújo, Trabalho e organização industrial num contexto de crise e reestruturação produtiva. In: São Paulo em Perspectiva. v. 8, n. 1, São Paulo: SEADE, jan/ mar., 1994, p.116-132.

CORSEUIL, Carlos Henrique e KUME, Honorio (coord) A Abertura Comercial Brasileira nos anos 1990: Impactos sobre emprego e salário. Rio de Janeiro: IPEA, Brasília: MTE, 2003.

COUTINHO, Luciano. A Terceira Revolução Industrial e Tecnológica: As grandes tendências de mudança. Economia e Sociedade. Campinas: UNICAMP/IE, n.1,agosto. 1992, p.69-87.

GIANOTTI, José Arthur et al. Reestruturação Industrial e modernização tecnológica, impactos 
Reestruturação produtiva em cidades médias:

uma análise das empresas industriais do Oeste Paulista, pp.93 - 103

sobre o mundo do trabalho. Cadernos de Pesquisa. São Paulo: CEBRAQ, n.1, jun., 1994, p.61-6.

GITAHY, Leda. Inovação tecnológica, subcontratação e mercado de trabalho. São Paulo em Perspectiva, v.8. n.1, Jan./ Mar. 1994, p.144-153.

GOMES, Maria Terezinha S. O processo de reestruturação produtiva em cidades médias do Oeste Paulista: Araçatuba, Birigui, Marília, Presidente Prudente e São José do Rio Preto. 2007. 330 f. Tese (doutorado em Geografia) Faculdade de Filosofia, Letras, Ciências Humanas, Universidade de São Paulo. São Paulo, 2007.

GUIMARÃES, Eduardo Augusto. Abertura econômica, estabilização e política industrial. In: VELLOSO, João Paulo dos Reis. (Org.) O real e o futuro da economia. Rio de Janeiro: José Olímpio, 1995.

HARVEY, David. A condição pós-moderna. São Paulo: Edições Loyola, 1992.349 p (versão em inglês, 1989)

Éditions Anthropos,1971.transformação: mudanças produtivas e atores sociais. São Paulo: Editora Fundação Perseu Abramo, 2003.221p

Reestruturação produtiva, novas tecnologias e novas formas de gestão da mãode-obra. In: 0 mundo do trabalho - crise e mudança no final do século. Campinas: Scritta, 1994, p.563-587.

LENCIONI, Sandra. Mudanças na metrópole de São Paulo (Brasil) e Transformações industriais. Revista do Departamento de Geografia, n.12, 1998a, p.27-42.

Reestruturação: uma noção fundamental para os estudos transformações e dinâmicas metropolitanas. In: VI ENCONTRO DE GEÓGRAFOS DA AMÉRICA LATINA. Anais. Buenos
Aires, Universidade de Buenos Aires, 1998b, p.110.

MOURÃO, Paulo Fernando Cirino. Reestruturação produtiva da indústria e desenvolvimento regional: a Região de Marília. 2002. 182 f. Tese (Doutorado em Geografia). Faculdade de Filosofia, Letras, Ciências Humanas, Universidade de São Paulo.São Paulo:USP. 2002.

NAVARRO, Vera Lucia. A reestruturação produtiva na indústria de calçados de couro em Franca (SP). In: ANTUNES, Ricardo e SILVA, Maria Moraes. O Avesso ao trabalho. São Paulo: Expressão Popular, 2004, p.78-152.

OLIVEIRA, Floriano José Godinho. Reestruturação Produtiva e regionalização da economia no território fluminense. 2003. 219 f. Tese (doutorado em Geografia). Faculdade de Filosofia, Letras, Ciências Humanas, Universidade de São Paulo. São Paulo:USP, 2003.

PIRES, Elson L. S. Mercado de trabalho e reestruturação produtiva na indústria: o Brasil no limiar do século XXI. Travessia. São Paulo: CEM, n.18, ano VII, 1994, p. 10-14.

RUAS, Roberto e ANTUNES, Elaine. Gestão do trabalho, qualidade total e comprometimento no cenário da reestruturação. In: Revista São Paulo em Perspectiva. Fundação SEADE. v.11, n.1, jan/ março. 1997, p. 42-53.

RUAS, Roberto. Reestruturação sócioeconômica, adaptação das empresas e gestão do trabalho. In: GITAHY, Leda (org.). Reestructuracion productiva, trabajo y educacion en America Latina. Campinas: Unicamp, 1994, p. 95-107.

SALERNO, Mario Sérgio. Reestruturação Industrial e Novos Padrões de Produção. São Paulo em Perspectiva. São Paulo: SEADE, v.6,n.3, 1992, p.100-108.

SCHUMPETER, Joseph A. A teoria do desenvolvimento econômico. São Paulo: Nova Cultural, 1989. (Coleção Os Economistas). 
SOJA, Edward W. Geografias Pós-modernas: a reafirmação do espaço na teoria social crítica. Rio de Janeiro: Jorge Zahar, 1993.324p

SOARES, Beatriz Ribeiro. Repensando as cidades médias brasileiras no contexto da globalização. Revista Formação. Presidente Prudente. n. 6. p.55-63. 1999.

SPOSITO, Maria Encarnação Beltrão (Org.). Textos e contextos para a leitura geográfica de uma cidade média Presidente Prudente: s.n, 2001, p.235-253.
- O chão em pedaços: urbanização, economia e cidades no estado de São Paulo. 2004. Tese (Livre docência). Faculdade de Ciências e Tecnologia. Universidade Estadual Paulista, Presidente Prudente.2004.

TEIXEIRA, Francisco J. S. e OLIVEIRA, Manfredo Araújo (org.) Neoliberalismo e reestruturação produtiva: as novas determinações do mundo do trabalho. $2^{a}$ ed. São Paulo: Cortez; Fortaleza:

Universidade Estadual do Ceará, 1998.252p

Trabalho enviado em dezembro de 2009 Trabalho aceito em junho de 2010 